\title{
Reparar nas coisas: de repente algo acontece e somos outro
}

\author{
Noticing things: \\ suddenly something happens and we are somebody else
}

\author{
Reparar en las cosas: \\ de repente algo sucede y somos otro
}

Rosane Preciosa ${ }^{2}$

\begin{abstract}
Resumo: O presente texto pretende partilhar algumas reflexões sobre o ato de pensar e escrever presente nas práticas acadêmicas atuais, que, na maioria das vezes, resultam em textos que operam uma quantidade enorme de informação e de citações, e, no entanto, a voz daquele que pensa e escreve encontra-se ausente. É como se pensarescrever seguisse um protocolo do bom uso de citações de autores recomendados sem que com elas a escritura se deixasse contagiar. O texto, no seu decorrer, vai afirmando exatamente o contrário disso: antes de mais nada, pensa-se implicado nas questões que se adensam no campo político e social e que nos perturbam de tal modo que é impossível não se interrogar sobre o que está nos acontecendo. O tom ensaístico adotado me pareceu oportuno pois se empenha muito mais em propor questões, sugerir caminhos e partilhá-los, do que evocar alguma certeza definitiva sobre o que narra. Além do mais, encoraja desvios no modo de produção da escritura, na medida em que acompanha o pensamento acontecendo. O que, decerto, não evita o risco de contradições e inacabamentos.
\end{abstract}

Palavras-chave: Pensar. Escrever. Práticas Acadêmicas.

Abstract: This text intends to share some reflections on the act of thinking and writing in the current academic practices, which, in most cases, result in texts that operate an enormous amount of information and quotations, and yet the voice of one who thinks and writes are absent. It is as though thinking-writing follows a protocol of good use of quotes from recommended authors without the scripture being allowed to be infected by them. The text, in the course of its course, states exactly the opposite of this: first of all, we think that we are involved in questions that grow in the political e social field and disturb us in such a way that it is impossible not to question ourselves about what is happening to us. The tone of the essay adopted seemed timely, because, and this is a characteristic of this genre of writing, he endeavors much more to propose questions, to suggest ways and to share them, than to evoke some definitive certainty about what he narrates. Moreover, it encourages deviations in the mode of writing as it accompanies the thinking that is taking place. This, of course, does not avoid the risk of contradictions and unfinished writing.

Keywords: Thinking. Writing. Academic Practices.

Resumen: El presente texto pretende compartir algunas reflexiones sobre el acto de pensar y escribir presente en las prácticas académicas actuales, que, en la mayoría de las veces, resultan en textos que operan una cantidad enorme de información y de citas, aunque la voz de aquel que piensa y escribe encuentra-se ausente. Es como si ambos pensar-escribir siguiera un protocolo del buen uso de citas de autores recomendados sin que con ellas la escritura se dejara contagiar. El texto, en su transcurso, va afirmando exactamente lo contrario: antes que nada, se piensa implicado en las cuestiones se piensa implicado en las cuestiones que se adhensan en el campo político y social y que nos perturban de tal modo que es imposible no interrogar sobre lo que nos está sucediendo. El tono de ensayo adoptado me pareció oportuno, porque se empeña mucho más en proponer cuestiones, sugerir caminos y compartirlos, que evocar cierta certeza definitiva sobre lo que narra. Además, alienta desviaciones en el modo de producción de la escritura, en la medida en que acompaña el pensamiento pasando. Lo que, ciertamente, no evita el riesgo de contradicciones y escrituras inacabadas.

Palabras clave: Pensar. Escribir. Prácticas Académicas.

\footnotetext{
${ }^{1}$ Submetido em: 15 fev. 2019 - Aceito em: 30 maio 2019 - Publicado em: 22 nov. 2019
}

${ }^{2}$ Universidade Federal de Juiz de Fora (UFJF) - E-mail: rosane_preciosa@yahoo.com.br 


\author{
Instrução Primeira \\ O conhecimento \\ está sempre \\ próximo do coração \\ (RICARDO MARQUES)
}

Estou sentada diante do computador, abro o word, a tela em branco me olha. Estou fumando um cigarro. Habitualmente não fumo. Essas duas ações, sentar e fumar, neste instante, se complementam. Acabo de ler no livro do escritor Gonçalo Manuel Tavares (2013) - "Atlas do Corpo e da Imaginação" - um fragmento de texto em que Picasso responde a uma pergunta que lhe é feita sobre o que seria necessário para ser pintor. Ele responde: se sentar. O outro, espantado, lhe diz: o senhor pinta sentado? Não, pinto sempre de pé. Mas, então, o que significaria esse sentar-se, na resposta de Picasso? Neste fragmento, Tavares (2013) nos conduz, sentar-se significa aguardar. Ingressar em um estado de preparação necessária, anterior a uma ação por vir. No meu caso, escrever um texto.

$\mathrm{O}$ encontro com este fragmento disparou algumas reflexões que vêm me acompanhando, faz tempo. A mais urgente delas, talvez o desejo de me alinhar a outra modalidade de temporalidade na vida cotidiana, mais compassada, menos urgente, menos imediatamente responsiva, empenhada em outras formas de pensar. Parar para ver, para escutar, para falar. Falas empenhadas em modos de dizer, em que as palavras não são meros porta-vozes de um lugar de certeza e funcionam muito mais como espaço de polinização de ideias. Refiro-me a certa corrente de ar fresco que uma fala, uma escritura, e, porque não dizer, que uma vida também deve fazer passar, de modo a desimpedir o pensamento, coagulado, aprisionado em modelos aprendidos em nossa trajetória escolar, em geral, tão sufocantes, estéreis, apenas reprodutivas.

Ao escolher a palavra polinização, fui remetida ao ensaio de Peter Pál Pelbart (2013), "Da Polinização em Filosofia", publicado no livro "O Avesso do Niilismo - Cartografias do Esgotamento". Em uma passagem o filósofo alude aos textos de Deleuze e Guattari como sopros que nos fazem atravessar tribos, faunas, floras. Textos que trazem movimento, assim como nos traz os de Pelbart, e que nos empurram para as beiradas da compreensão. Isso me é caro, porque o sentido que esses filósofos pretendem dar ao que enunciam é de uma precisa imprecisão. Predomina uma plasticidade no pensamento, que interpreto como um chamamento para que cada um escreva linhas de leitura a partir da posição singular que cada sujeito vai ocupando no mundo. Ao menos para mim, fica sempre a impressão de que esses autores solicitam que eu me torne um agente vivo de produção de ideias, fazendo operar lógicas associativas. Que eu me sente por um instante numa posição confortável e sinta na pele que espécie de corrente de ar produz aquele texto em mim. O que ele deseja de mim? Que apenas o reproduza com perfeição? Ou que eu o entorte, trazendo para seu convívio alteridades, outras vozes, outros timbres, que ponham mais lenha na fogueira desse sistema, que, no meu entender, estimula a fricção com outros corpos, que não deseja ser centro absoluto de nada, que admite ser infectado.

Expandir esse sistema requer estar à espreita de presenças, portadoras de outros ares que forçam deslocamentos no modo habitual de pensar, de sentir, de viver. Aliás, o próprio 
Deleuze, na condição de filósofo, cria conceitos que não estão circunscritos à história da filosofia, é toda uma combinatória com outros planos de saber que impulsionam a criação de seus conceitos filosóficos. Seu pensamento está sempre implicado com alguma questão que lhe interessa, não se trata nunca de um exercício neutro, de um mero pensar por pensar. Falar em um pensamento implicado em Deleuze significa falar de uma produção de conceitos cuja finalidade é intervir no mundo. Seu modo de operar é lançando-se para fora da filosofia, farejando em outros lugares, na literatura, na pintura, no cinema, na psicanálise, operadores para maquinar seus conceitos, submetendo-os a torções necessárias, fazendo-os funcionar sob a perspectiva do que lhe interessa maquinar. Há outros mundos possíveis para emergir, ainda que se pense ser este, funcionando sob a lógica capitalista neoliberal, o único. Afinal, ele conta com toda a máquina publicitária e midiática para validá-lo e reproduzi-lo. Naturalizado, difícil questioná-lo.

Alguns minutos atrás fazia muito calor no quarto onde escrevo, e subitamente começa a ventar. Meu corpo antes estacionado no calor se distende aliviado. Vou dar uma corridinha na janela saudar esse vento benfazejo. Ando perdendo o medo de parecer tola diante dos outros, sobretudo diante dos meus alunos, ao incorporar uma fala ou um gesto deslocado da expectativa do que em geral se tem do que seja uma aula. Ando me arriscando a parecer esquisita, atenta ao que me atravessa o espírito durante o momento das aulas: um barulho do cortador de grama do lado de fora, um vira-lata que entra pela porta da sala, uma luz soberba de fim de tarde, um trejeito gracioso de algum aluno, um desejo súbito de entoar uma canção ou ler um poema. Acredito que exista algo contíguo entre a aula que preparei em casa e esses pequenos ruídos que imprimem movimento ao que ensaiei. A intensidade da vida se faz presente o tempo todo na nossa existência e desconcerta o planejado. Gosto de pensar que aquele sujeito que está ali, diante de todos, partilhando suas leituras, por vezes se distrai, sai do roteiro e o retoma de outro jeito. Incorporou à sua fala, o que lhe aconteceu.

Mas qual seria a expectativa dominante dos alunos na maioria das vezes? A de que o professor vai passar informações que sejam úteis e indispensáveis à sua formação acadêmica. E quanto maior o volume de informações acumuladas, mais instrumentalizados estarão para azeitar o mercado capitalista neoliberal, que se regozija em arregimentar a força produtiva de sujeitos entupidos de informações, absolutamente incapazes de dar sentido ao que lhes acontece e ao que acontece à sua volta. São ativos demais, assertivos demais, têm opiniões demais, estão circunscritos ao próprio umbigo. Essa vem sendo a tendência majoritária da educação vigente. Nela, a concepção de aula, com seus conteúdos fixos instituídos, e pouco interrogada criticamente, supõe que tudo que ali está sendo apresentado é o que convém indistintamente a todos, que forma a base homogênea da educação de todos. Que cada um, então, trate de anotar tudo, para reproduzir bem bonitinho depois.

Nos anos 1980, uma aluna de Gilles Deleuze, Claire Parnet, com quem ele escreveu um livro, que recebeu o título de "Diálogos" em português (DELEUZE; PARNET, 1998), propõe ao filósofo realizar uma entrevista-filmagem em que ele elegesse temas de $\mathrm{A}$ a $\mathrm{Z}$ que lhe são caros e discorresse filosoficamente e bem à vontade sobre eles. O título dessa conversação é "Abecedário", disponível no youtube. Na letra P de Professor, Deleuze nos dirá coisas que destoam bastante do modo como tradicionalmente a gente pensa uma aula. Eu vou elencar aqui algumas frases que me fisgaram. Ele trata a aula como algo musical, em que cada um extrai 
aquilo que lhe convém. Algumas pessoas, por exemplo, caem no sono e acordam misteriosamente no momento em que algo lhes interessa. Para ele, não são exatamente os assuntos que são interessantes, mas algo mais. Também dirá que numa aula a inteligência e emoção comparecem em equilíbrio, e Deleuze dá destaque à emoção. Uma aula sem emoção é desinteressante. $\mathrm{O}$ algo mais seria então transmitido pelo gradiente de emoção que circula numa aula. Não podemos nos esquecer que existe na tradição filosófica, que herdamos, uma terrível suspeita quanto à emoção. Ela nos induziria ao erro e à imprecisão, à falha, faltaria-lhe ordem e equilíbrio. Mas Deleuze descredita essa cisão inteligência-emoção, e reconduz a inteligência aos braços da emoção. Ela, que tem a força de fazer vibrar o corpo, e esse encontro resulta em palavras vivas, contagiantes, que vão construindo modos de desenhar o pensamento na contramão de automatismos e normatizações. São palavras com gente dentro, empenhadas em abrir territórios de saber e de convívio inexplorados. Palavras que desejam formular um jeito desacostumado de pensar.

Estimulante pensar numa aula assim, como uma partitura musical, atravessada pela emoção e inteligência, em que vozes vão criando tramas, tecidas por fios que são as experiências singulares que os sujeitos carregam: os livros lidos, os filmes assistidos, as cidades que serviram de pousada, os bares frequentados, as bocas beijadas, as camas dormidas. Um espaço como esse, em que a trama das vozes, umas mais graves, outras mais agudas, e com seus diferentes timbres, uns mais aveludados, outros mais ásperos, jamais será uma massa homogênea, porque cada existência é única, singular, finita.

Inúmeros são os pensadores que hoje se debruçam sobre os efeitos devastadores do regime capitalista neoliberal no ambiente natural. Há dois exemplos muito vivos em nós, que nos causam muita dor: o rompimento da barragem de rejeitos da mineradora Samarco, ocorrido em Mariana, no ano de 2015, e o rompimento de outra barragem, da Vale do Rio Doce, que atingiu Brumadinho, em janeiro de 2019. Embora, pareça, que muitos não se deem conta, esses acontecimentos respingam lama na subjetividade. Guattari (1990) em seu livro "As Três Ecologias”, publicado em 1989 na França, e, no Brasil, em 1990, já nos chamava a atenção para o entrosamento e articulação dessas três esferas: a ecológica, a pública, referindo-se aos laços sociais tecidos entre os sujeitos e a da subjetividade. E pensar a possibilidade de criação de outros territórios de existência implicaria revolucionar, palavra difícil essa de se empregar hoje em dia, essas três instâncias.

\footnotetext{
Não haverá verdadeira resposta à crise ecológica a não ser em escala planetária e com a condição de que se opere uma autêntica revolução política, social e cultural reorientando os objetivos de produção de bens materiais e imateriais. Essa revolução deverá concernir, portanto, não só às relações de forças visíveis em grande escala, mas também aos domínios moleculares de sensibilidade, inteligência e de desejo (GUATTARI, 1990, p. 9).
}

Nos limites desse texto, gostaria de puxar o fio da subjetividade, para prosseguir numa direção que vem se insinuando, tomara, ao longo do texto. Ela diz respeito aos atos de pensar e escrever, exercitados pelos alunos, mas, talvez, pudéssemos incluir, também nós, professores. Observo que, cada vez mais, se encoraja o aluno a reunir um amontoado de informações, que culminam em opiniões, em geral, categóricas, que fulminam o texto. Este, então, traduz-se numa massa compacta finalizada, pronta para consumo, não deixa brechas para uma conversação. E por que não permite uma aproximação com o outro? 
Depois de assistir a uma aula ou a uma conferência, depois de ter lido um livro ou uma informação, depois de ter feito uma viagem [...], podemos dizer que sabemos coisas que antes não sabíamos, que temos mais informação sobre alguma coisa; mas, ao mesmo tempo, podemos dizer que nada nos tocou [...], nada nos sucedeu ou nos aconteceu (LARROSA, 2014, p. 19).

Há, hoje, consolidado nas práticas do pensar e do escrever acadêmicos, uma espécie de coerção: a de comunicar rapidamente alguma ideia, apresentar um resultado para ser avaliado. É redundante dizer que vivemos numa sociedade com um fluxo vertiginoso de informações, que nos leva de cambulhada. A sensação que se instala é a de que é preciso processar tudo rapidamente para despachar respostas, convicções. O trabalho de recepção voraz de fontes bibliográficas, de citações, encolhe, me parece, o espaço para que outro trabalho, este sobre si mesmo, se realize. Isso implicaria para começo de conversa admitir que alguém pensa e escreve a partir de uma tomada de posição diante de questões, suscitadas no mundo, que convocam esse alguém a pensar-escrever. E, decerto, são questões que se insinuam num sujeito singular, com práticas singulares de vida, que trazem alguma inquietação, algum incômodo e perplexidade, e, por isso ele escreve, justamente não para se livrar do desconforto, mas para interrogá-lo de perto. Para exercitar-se em outros diagramas de existência possíveis. Melhor dizendo, para fabular outros enredos vivíveis, e poder partilhá-los com outros pensadores.

No texto de Jorge Larrosa (2014), existe uma intenção muito precisa de distinguir informação de experiência. Não vou entrar nos meandros da discussão que ele traz, aliás oportuna, enriquecedora e bem mais complexa do que me apropriarei aqui, para refletir sobre o que andamos nomeando como produção de conhecimento. E isso diz respeito, me parece, não só aos nossos alunos, mas sobretudo a nós, professores, que muitas vezes escrevemos nossas ideias com palavras neutras, como se quiséssemos apagar o rastro de que há alguém vivo, pulsante, ali habitando essas palavras. Bom, mas temos sido ensinados a não contaminarmos nossos textos, é cientificamente incorreto, não é técnico. O mais curioso de tudo isso é que, ao despistar nossa voz, subtraímos do texto o rastro de alegria que as vozes alheias nos proporcionaram e garantiram nossa transformação.

Para Larrosa (2014), o sujeito da experiência, diferentemente do sujeito da informação, é alguém vulnerável ao que lhe acontece. A vulnerabilidade me parece um ponto chave, porque diz respeito a uma outra lógica em jogo, o da desaceleração, e implica uma parada para uma escuta de si e do outro e do mundo à volta. A avidez em acumular dados e disparar opiniões aqui não são cogitadas, nem levadas em conta.

Destaco do texto de Jorge Larrosa duas citações relevantes:

Nós somos sujeitos ultrainformados, transbordantes de opiniões, superestimulados [...] estamos sempre em atividade porque estamos sempre mobilizados, não podemos parar (LARROSA, 2014, p. 24).

O sujeito da experiência se define não por sua atividade, mas por sua passividade, por sua receptividade, por sua disponibilidade, por sua abertura. Trata-se, porém, de uma passividade anterior à oposição entre passivo e ativo, de uma passividade feita de paixão, de padecimento, de paciência, de atenção [...] (LARROSA, 2014, p. 26).

Mergulhados no excesso de atividade, de iniciativa, de afoiteza em tirar logo conclusões sobre o que lemos, nos vemos inteiramente capturados pela lógica da informação, que domina 
nosso modo de existir, e que nos traz a sensação confortante de que estamos por dentro de tudo, somos muito inteligentes, mas que, de fato, só resultou em barulho pensado e escrito. Por outro lado, aventurar-se por esse estranho caminho de passiva atividade pode se traduzir numa espécie de alforria desse esquema hegemônico de produção de pensamento, em que caímos todos, alunos e professores, que, no final das contas, se satisfaz com os resultados apresentados em textos, onde inexiste sutileza alguma de pensamento, sequer apontam outros horizontes para quem os lê.

Passividade feita de paixão, de paciência, de atenção, três palavras inestimáveis articuladas por Larrosa (2014), que em nossas práticas cotidianas de ensino parecem encontrar pouco lugar para se expandir. Sobretudo porque estão a serviço de outra modalidade de produção de saber, aquela comprometida com a vida. Nesse sentido, retomando uma das ideias contidas no início desse texto, não se pensa por pensar, pensa-se implicado nas questões que nos desafiam a pensar. No entanto, não é isso o que nos vem sendo ensinado a praticar. Somos submetidos desde crianças a reproduzir conteúdos, comunicando de forma objetiva e clara o que pensamos, utilizando a língua de modo meramente instrumental. Esse é o modelo de escrita acadêmica herdado. Narrar ou ensaiar, é fazer literatura. Que o texto não venha respingado de emoção. E a emoção da qual estou falando é aquela que, suponho, para Deleuze, assessora a inteligência, entortando sua condução reta, bagunçando sua pretensa convicção sobre tudo.

Já a paciência e a atenção vão inteiramente na contramão das práticas educacionais disseminadas hoje em dia. Ambas atritam com a lógica dos resultados instantâneos, baseada no acúmulo de dados colhidos, prontos para usar. Operam à escuta do que lhes interpela enquanto viventes, e que lhes solicita uma tomada de posição, uma ética.

A escola vem se encarregando em moldar a subjetividade, aplainando vozes, despotencializando aquelas que ousam afrontar seu funcionamento, reivindicando autonomia para pensar e modos de dizer distintos do que se espera. Boa parte de nós fomos formados de acordo com essas diretrizes. Não é fácil se desembaraçar desse legado e se autorizar a pensarescrever com suas incertezas e possíveis erros, e, sobretudo, sustentar as dúvidas. Somos estimulados a cultivar uma inteligência atlética, que disserta com propriedade sobre o tema escolhido, cujo texto escrito parece ter esquecido o sujeito do lado de fora.

Por fim, talvez fosse o caso de se perguntar: o que buscamos em nossas aulas e orientações? Inventar com os alunos um campo propício a especulações que transitem por múltiplas perspectivas de pensar-escrever, e tracem centros de equilíbrio deliberadamente instáveis? Por que não acolher, inclusive, alguns disparates que acometem o exercício do pensar, sem apressadamente enxotá-los? Talvez seja necessário estimular nos alunos, e, antes de tudo, em nós professores, a produção de discursos singulares, tecido de abalos, dúvidas, hesitações, porque pensamento algum está pronto de antemão. Como se é interpelado a pensar, trata-se de um exercício. E o que se pretende é transmitir para além dos resultados os processos que conduziram alguém por caminhos que desconhecia, os quais foi acessando com atenção e paciência aos poucos, e se aproximando, no final das contas, de si mesmo, e de certo entendimento de mundo que convocava nele a urgência de alguma espécie de decifração. 


\section{Referências}

DELEUZE, Gilles; PARNET, Claire. Diálogos. Tradução de Eloísa Ribeiro. São Paulo: Escuta, 1998.

GUATTARI, Félix. As Três Ecologias. Tradução de Maria Cristina F. Bittencourt. Campinas: Papirus, 1990.

LARROSA, Jorge. Tremores - escritos sobre experiência. Belo Horizonte: Autêntica, 2014.

PELBART, Peter Pál. Da Polinização em Filosofia [Deleuze]. In: PELBART, Peter Pál. O avesso do niilismo: Cartografias do esgotamento. São Paulo: N-1 edições, 2013. p. 371-390.

TAVARES, Gonçalo Manuel. Atlas do corpo e da imaginação: teoria, fragmentos e imagens. Portugal: Editorial Caminho, 2013. 